Departamento de Anatomia Patológica

Diretor: Prof. Dr. Altino A. A. Antunes

\title{
CORPOS ESTRANHOS NAS VIAS BILIARES
}

\author{
POR
}

\section{Euclydes Onofre Martins}

Assistente

Com estampas II-V

Em revisão no arquivo de peças do laboratório, encontramos uma cuja publicação julgamos interessar: trata-se de um fígado de porco, pesando 2,489 grs., medindo $36 \mathrm{cms}$. em seu diâmetro longitudinal, $23 \mathrm{cms}$. no diâmetro transversal e $6 \mathrm{cms}$. de espessura.

Descrição da peça: - A superfície externa, tanto parietal como visceral, apresenta-se lisa, notando-se porem, por baixo da cápsula de Glisson, sombras em formas de cordões, acinzentadas, e, em alguns lugares, ligeiramente salientes, de espessura variavel, diminuindo, à medida que se ramificam em direção dos bordos do fígado. A consistência do orgão estava aumentada, e, em certas zonas, à palpação, verificava-se uma ligeira crepitação, especialmente nas mencionadas sombras.

No hilo do orgão, verificou-se estar o colédoco grandemente dilatado, com suas paredes muito espessadas e cheio de um material granuloso, assemelhando-se muito ao pedregulho miudo. Não foi possivel o estudo da vesícula biliar e conduto cístico, pois, ambos faltavam na peça.

Efetuamos cortes em várias direções, notando-se que a faca rangia como se cortasse areia. Os canais biliares, em sua quasi totalidade, estavam extremamente dilatados, e as suas paredes bastante espessadas, chegando, em alguns lugares, até a $2 \mathrm{mms}$. de espessura; continham o mesmo material arenoso que enchia o colédoco (Fig. 1).

Alguns dutos biliares, embora dilatados, não continham tal material, enquanto outros, estavam cheios de uma substância caseosa, só ou de mistura com areia.

O material em questão era formado por partículas duras e granulosas de vários tamanhos, indo desde o aspecto de areia, até o de pedregulho, tendo em média $5 \mathrm{mms}$. de diâmetro. Sua coloração, em geral, era branca, havendo porem alguns grânulos pretos e marrons. Esses grânulos se desprendiam facilmente, embora houvesse uma substância caseosa em maior ou menor quantidade que os unisse.

Esvasiados os canais biliares intra-hepáticos, pudemos verificar que, em suas paredes espessadas, haviam ficado impressas as for- 
mas dos corpos estranhos, apresentando assim um aspecto reticulado. (Fig. 2).

O exame do material colhido nos canais biliares dilatados, foi feito na Escola Politécnica, que nos forneceu o seguinte resultado: "Predominância de areia (quartzo) cerca de 99\%. Fragmentos de hematita e magnetita. Alguns fragmentos revestidos de matéria orgânica azotada".

O exame histológico foi feito em fragmentos retirados em várias alturas do orgão, corando-se pela hematoxilina-eosina e mucicarmim, após fixação em formol e inclusão em parafina.

RElatóRIo histológico: - Trata-se de um corte de fígado de porco, onde a parte normal se apresenta com seus lóbulos bem nítidos, destacados e separados por tecido conjuntivo frouxo, pouco abundante. Mesmo nessa parte normal, notam-se os vasos sanguíneos, veia central e vasos dos espaços de Kiernam, cheios de hemátias. Partindo dessa zona para onde se encontram as lesões, deparamos logo com um tecido conjuntivo fibroso, abundante, que, em geral, em alguns pontos, dá a impressão de uma cápsula circunscrevendo as lesões. Esse tecido conjuntivo se extende muito alem dessas zonas, reproduzindo em conjunto o quadro de uma cirrose. Nas zonas cirróticas, encontramos ilhotas de parênquima hepático desorganizado na sua estrutura, com imagem lobular inteiramente apagada, mostrando, porem, ainda as colunas de Remak alteradas, mas, bem diagnosticáveis.

Os espaços de Kiernam são perfeitamente reconhecíveis, mostrando vasos dilatados e cheios de sangue e dutos biliares com parede espessa em muitas zonas e dilatados em outras. Ao lado desses elementos, encontramos, algumas dilatações císticas de tamanhos variáveis, desde muito pequenas, até bem grandes, revestidas por uma camada única de epitélio cúbico, estando, na maioria, vasias; em outras, nota-se uma substância homogênea, de aspecto mucoso, não se corando eletivamente pelo mucicarmim. Em algumas dessas formações, nota-se uma substância mais densa, tambem corada em roseo pela eosina, mas, impregnada por sais de cálcio, corado em roxo-azulado pela hematoxilina. Essas dilatações foram tambem, raramente, encontradas na parte normal do orgão. Pensamos tratar-se de formações císticas provavelmente congênitas.

Nas dilatações encontradas na parte lesada, várias imagens foram observadas: - a) - algumas são simples, com epitélio cúbico por vezes achatado, ausente, muitas vezes, total ou parcialmente, lembrando o que se costuma observar nos cistos de retenção (Fig. 3) ; b) -- outras apresentam suas paredes proliferadas, com duas ou mais 
camadas de epitélio cúbico ou cilíndrico, rodeando uma cavidade bastante grande, vasia ou parcialmente cheia por uma substância que se cora em roseo pela eosina, e não dá reação específica pelo mucicar$\operatorname{mim}$; c) - outras, ainda, apresentam proliferação muito maior, de tipo papilífero (Fig. 4 e 5), lembrando a imagem dos cistomas papilíferos do ovário, e, em algumas dessas, a proliferação é mais diferenciada, havendo formações glandulares do tipo adenomatoso, justificando o conceito de JoEST que admite a possibilidade de a inflamação produzida por corpos estranhos das vias biliares levar até à formação adenomatosa; d) - em outras formações, não se vê epitélio nem o tecido fibroso sub-epitelial das anteriormente descritas, mas, rodeando a cavidade, encontra-se um abundante exsudato inflamatório, constituido em mor parte de linfocitos, tendo presentes plasmocitos e neutrófilos (Fig. 6 e 7). Esse exsudato infiltra o tecido conjuntivo que delimita a cavidade, e, vai mais longe ainda, infiltrando até o parênquima hepático das zonas normais próximas. Trata-se aquí de uma reação inflamatória de tipo crônico, provavelmente determinada pelo corpo estranho.

Chama atenção tambem, em todo o corte, a espessura grande das paredes arteriais e a presença constante de hemátias em quase todos os vasos, quer venosos como arteriais e capilares.

DIAGNóstico: - Dilatação cística por corpo estranho (?) com inflamação crônica hiperplástica, congestão e cirrose.

INCIDÊNCIA: - Na literatura que pudemos compulsar, poucos foram os casos encontrados e, das citações, verificamos haver pequeno número deles descrito. Assim, foi observado o enchimento das vias biliares pelo mesmo material por nós encontrado, em porco (Jozst), novilha (GUILlebeAU, RABISON), veado (KITT), cavalo (MÜlLLER), carneiro (BUGGE e LIEBIG).

Alem das vias biliares, a vesícula biliar pode estar cheia de areia e outros corpos estranhos. DELUDin achou em vesícula biliar de uma vaca, areia granulada de rio, pedacinhos de pedra, ossos, etc., com o peso total de $650 \mathrm{grs}$.. JoEst encontrou duas partes de espiga de centeio na vesícula biliar de um porco. KinzLEY observou na vesícula biliar de vários porcos, que se achavam otimamente nutridos, quantidade de areia variando de $30-1.000$ grs.. GURLT encontrou na vesícula biliar de um porco uma "infinidade de areia e pedregulho".

Do mesmo modo que a areia, pode penetrar, excepcionalmente, o conteudo intestinal comum, nas vias biliares, assim como na vesícula biliar. Foi observado isso em uma novilha (JoEst). 
Pode tambem haver penetração de corpos estranhos na vesícula biliar, mas, raramente nas vias biliares intra-hepáticas, pela perfuração da parede gástrica e tambem da intestinal, por pregos, agulhas, arame, etc.. Isso foi observado no porco e na novilha (JoEST).

A quantidade de areia pode atingir volume consideravel. RABISON achou na vesícula biliar e vias biliares intra-hepáticas de uma novilha, perto de 4 quilos de areia.

Contam-se ainda entre os corpos estranhos, os entozoários, que casualmente penetram nas vias biliares. Em um cão novo, infestado em alto grau pelo Ascaris canis, JoEST achou a vesícula biliar cheia e dilatada, contendo 9 vermes, enquanto que 2 ficaram no duto hepático e 1 no duto colédoco. Stefani encontrou na vesícula biliar de um porco um Echinorrhynchos gigas, de tamanho normal. VogELSANG observou na vesícula biliar de um cão um exemplar de Dipyllidium caninum de $12 \mathrm{cms}$. de comprimento.

PATOGENIA: - Não são conhecidas as condições em que se processa a passagem dos corpos estranhos às vias biliares. Para BUGGE e LIEBIG é importante a situação da embocadura do duto colédoco e de sua largura anormal. GuRLt é de opinião que os corpos estranhos sejam lançados nos condutos biliares por contrações do duodeno. JoEST considera ser a implantação anormal do colédoco na parede ventral do duodeno, fator que explica facilmente a penetração nesse duto, da areia acumulada por seu próprio peso nas porções mais decliveis daquela porção intestinal. Uma vez no duto colédoco, a areia pode aí permanecer, mas, em geral, progride, alcançando assim o duto hepático, o cístico e a vesícula biliar. JoEST procura explicar esse andamento do corpo estranho em sentido contrario á corrente biliar, como resultante da ativação das contrações antiperistálticas do colédoco e do hepático por uma pressão anormal do duodeno e pela pressão exercida pela nova entrada de outros corpos estranhos na embocadura do colédoco.

Pelo que observamos no exame dos cortes histológicos, admitimos u'a mal formação congênita das vias biliares. Como a areia nos animais, quase sempre é parte essencial do conteudo intestinal, encontrando dilatação anormal ou má implantação do duto colédoco, ou ambas, ou se servindo da dilatação do esfincter de Oddi que o jejum produz, pelas contrações do duodeno, penetra em suas primeiras porções e daí, pelo seu peso e pelas contrações disperistálticas do duto colédoco, caminha até às vias biliares extra e intra-hepáticas.

RESUMO

No presente trabalho o A. estuda um caso de presença de areia e pedregulho miudo, nas vias biliares dilatadas de um porco. Faz a 
descrição macroscópica da peça e o estudo histológico de fragmentos do orgão, colhidos em vários pontos.

A análise do material retirado dos canais biliares dilatados, revelou tratar-se de areia com $99 \%$ de quartzo.

O exame microscópico mostrou tratar-se de uma dilatação cística por corpo estranho (?) com inflamação erônica hiperplástica, congestão e cirrose.

Estuda a patogenia do processo, citando as opiniões de BUGGE, LIEBIG e GURLT e pensa no presente caso, haver mal formação congênita das vias biliares, facilitando assim a penetração da areia, impelida para o colédoco pelo seu próprio peso e pela contração do duodeno, aliados ao disperistaltismo do duto e relaxamento, pelo jejum ou por outra causa, do esfincter de Oddi.

\section{SUMMARY}

This paper deals with a case of sand and fine gravel being found in the dilated bile ducts of a pig. The macroscopic description of the liver is given together with the histological report of the liver fragments taken from various sections.

The chemical analysis of the material secured from the dilated bile ducts disclosed the presence of sand containing $99 \%$ of quartz.

The microscopic examination shoved a kystic dilation caused by a foreign body (?) with hyperplastic chronic inflammation, congestion and cirrhosis.

The pathogeny of the process involved is discussed in the light of Bugge's, Liebig's and Gurlt's opinions. In the case under consideration there seems to be a congenital malformation of the bile ducts, which would have facilitated the entering of the sand, impelled through the duot both by its own weight and by the duodenum contraction, and, perhaps, also by the dysperistaltic contractions of the duct and the relaxation of Oddi's sphincter caused by the fast or some other reason.

\section{BIBLIOGRAFIA}

Aschoff, L. - 1934 - Tratado de Anatomia Patologica. Trad. 7. ${ }^{\mathrm{a}}$ ed. alemana. 2, 968. Barcelona, Editorial Labor, S.A.

Gulllebead, A. - 1900 - Die Rückstauung von Sand und Steinchen aus dem Verdauungskanal in die Gallenwege. Schw. Arch. Tierhlk., 42 (6):248/9.

Hofrmann, J. A. - 1934 - Ein fingerlanger Draht in der Leber eines Sehweines. Münch. tierarztl. Wschr., 50:596.

JoEst, E. - 1937 - Handbuch der speziellen pathologischen Anatomie der Haustiere. 2(1):41/44. 2 Aufl. Berlin, Richard Schoetz.

Кгтт, Тн. - 1923 - Lehrbuch der pathologischen Anatomie der Haustiere. $2: 108$. 5 Aufl. Stuttgart, Ferdinand Enke. 


\section{EXPLICAÇÃO DAS FIGURAS}

\section{Estampa II}

Fig. 1 - Duas superfícies de córte do fígado, mostrando as dilatações cheias de arêia e canais dilatados vasios.

Fig. 2 - Duas superfícies de córte, corresponde à fig. 1, depois de esvasiado de seu conteúdo, mostrando o aspecto reticulado da parede de algumas dilatações.

\section{Estampa III}

Fig. 3 - Grande cisto revestido por uma só camada de epitélio cúbico. (obj. 20 oc.4).

Fig. 4 - Cisto com proliferação adenomatosa da parede, vendo-se ao lado um cisto menor forrado por uma camada de epitélio cúbico e acima dêste uma artéria com a parede enormemente espessada. (obj. mikrotar $6 \mathrm{cms}$.).

\section{Estampa IV}

Fig. 5 - Micro com maior aumento de parte da parede do cisto grande da fig. 4, mostrando detalhes de sua estrutura. (obj. 40 oc. 4).

Fig. 6 - Cisto cuja parede está totalmente constituida por exsudato inflamatório que infiltra profundamente o tecido. (obj. 20 oc.4).

\section{Estampa V}

Fig. 7 - Detalhes com maior aumento da fig. 6 (obj. 40 oc. 4). 


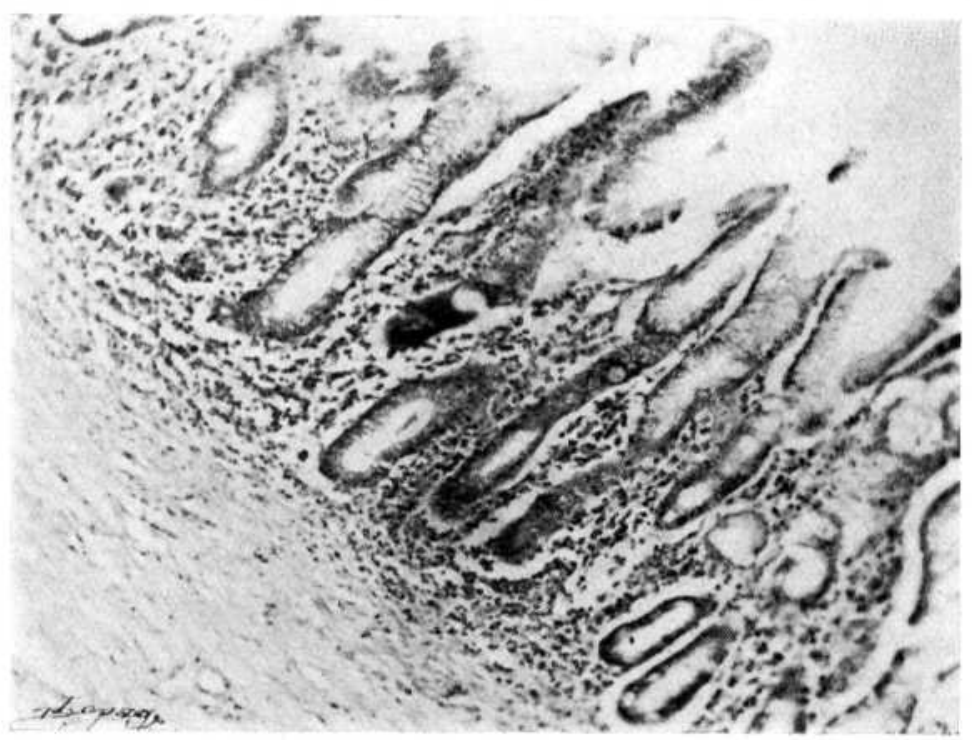

5

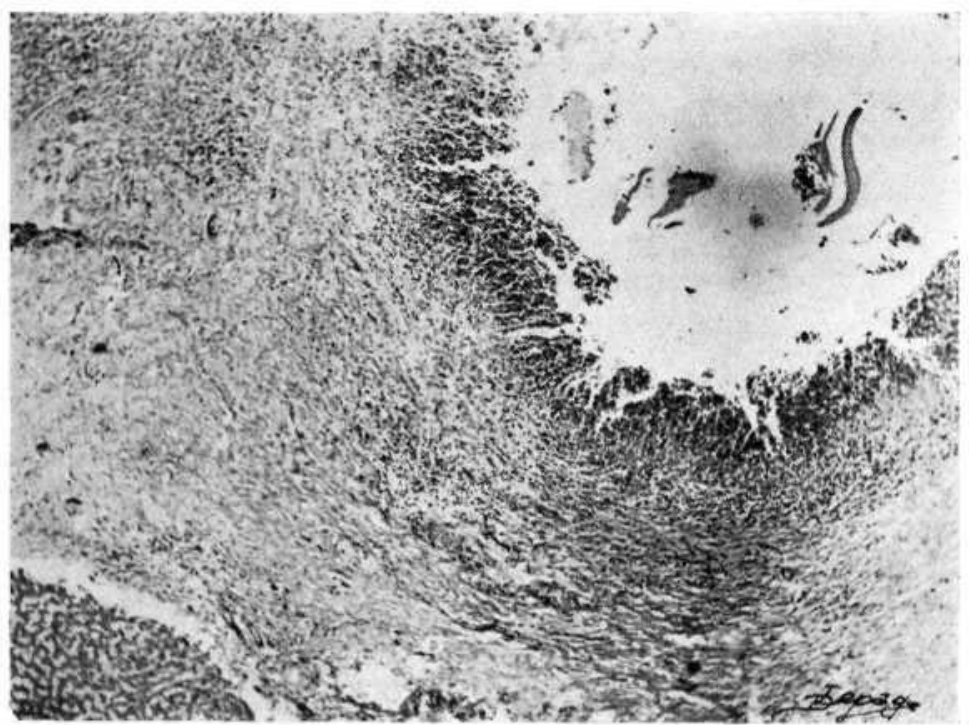


Euclydes Onofre Martins,

Corpos estranhos nas vias biliares
Rev. Fac. Med, Vet. S. Paulo, Vol. 2, fase, 2

Est. V

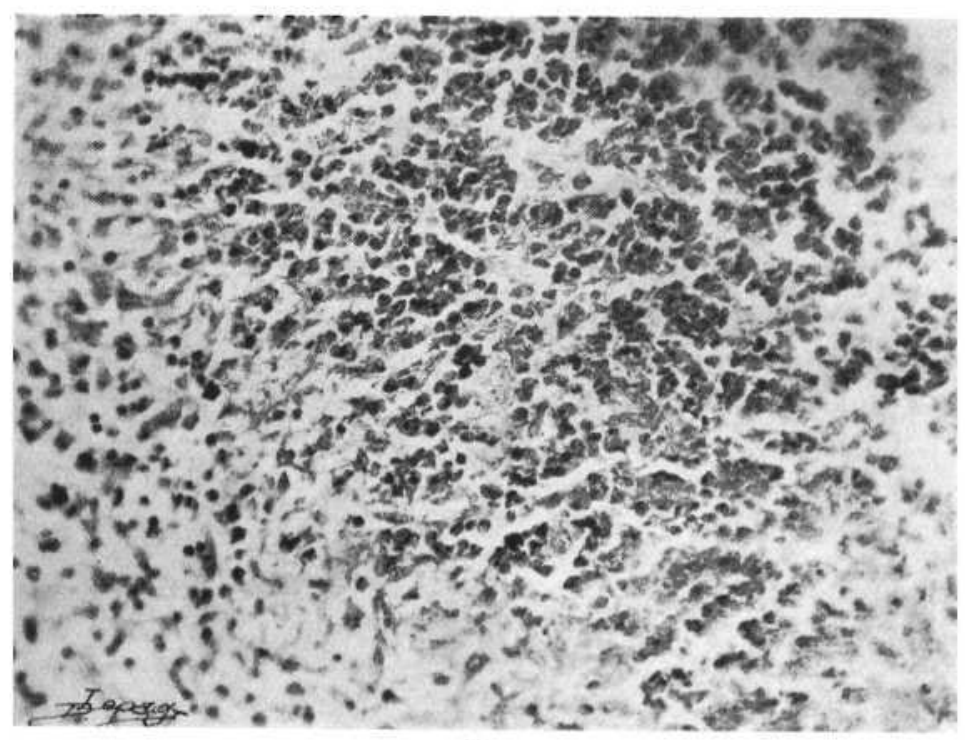

